\title{
PENGARUH PERLAKUAN PANAS QUENCHING DAN TEMPERING TERHADAP LAJU KOROSI PADA BAJA AISI 420
}

\author{
Sotya Anggoro \\ Prodi Teknik Mesin Program Vokasi Universitas Muhammadiyah Yogyakarta (UMY) \\ E-Mail : anggapmy@gmail.com \\ Jl. Lingkar Selatan Tamantirto Kasihan Bantul
}

\begin{abstract}
Corrosion occurs in almost all metals. Even corrosion-resistant metals are corroded, but their corrosion rate is different from ordinary or non-corrosion resistant metals. This study examines the corrosion rate that occurs in stainless steel that is stainless steel. Stainless steel contains high enough chromium levels that can reduce the rate of corrosion that occurs. The metal material to be studied is the AISI 420 steel, which belongs to the Martensitic Stainless Steel class. This study examined the effect of heat treatment on corrosion rate and hardness level of AISI 420 steel.

The heat treatment carried out was Quenching at $1020^{\circ} \mathrm{C}$ with a holding time of 60minutes with an oil cooling medium. After quenching the subsequent heat treatment is tempering with temperature variations of temperature $200^{\circ} \mathrm{C}$ and $300^{\circ} \mathrm{C}$ with a resistance time of 45 minutes and air cooling media.

The results of this study showed that the base material specimens had the highest corrosion rate of $0.569 \mathrm{~mm} / y$. The lowest corrosion rate is in specimens with quenching process with a value of $0.267 \mathrm{~mm} / \mathrm{y}$. The highest Vickers hardness values were found in specimens with quenching process with a value of $551 \mathrm{~kg} / \mathrm{mm} 2$. The lowest hardness value is in the specimen with tempering process at $300^{\circ} \mathrm{C}$ with $405 \mathrm{~kg} / \mathrm{mm} 2$.
\end{abstract}

Keywords: Heat Treatment, Quenching, Tempering, Stainless steel, Corrosion.

\section{PENDAHULUAN}

Hampir disetiap bidang kehidupan manusia menggunakan alat bantu yang alat tersebut digunakan untuk mempermudah kehidupan manusia. Sudah sejak dahulu konstruksi berbagai alat yang digunakan manusia menggunakan logam sebagai komponen utamanya. Pada logam ini dapat terjadi korosi yang akan menyebabkan kualitas bahan tersebut menurun yang akhirnya dapat menyebabkan kegagalan.

Dalam peristiwa korosi, ada dua hal yang dapat digunakan untuk membedakan atau membagi korosi itu menjadi dua yaitu korosi yang disebabkan atau berasal dari bahan itu sendiri dan korosi yang disebabkan dari lingkungan. Faktor dari bahan meliputi kemurnian bahan, struktur bahan, bentuk kristal, unsur-unsur kimia yang ada dalam bahan, teknik pencampuran bahan dan sebagainya. Sedangkan faktor yang berasal dari lingkungan meliputi tingkat pencemaran udara, suhu, kelembaban, keberadaan zat-zat kimia yang bersifat korosif dan sebagainya.

Korosi merupakan penyebab utama kerusakan pada suatu konstruksi yang menggunakan bahan logam, atau yang sebagian besar komponennya memakai bahan logam. Bahan-bahan korosif yaitu yang dapat menyebabkan korosi terdiri atas asam, basa serta garam, baik dalam bentuk senyawa anorganik maupun organik.

Dari sekian banyak penyebab korosi dari lingkungan, hujan asam merupakan salah satu pencemaran udara yang dapat mengakibatkan korosi pada logam. 


\section{LANDASAN TEORI}

Baja merupakan salah satu jenis logam yang banyak terdapat di muka Bumi ini. Jenis logam ini juga dapat mengalami korosi. komponen utama dari baja adalah besi $(\mathrm{Fe})$ dengan karbon (C) sebagai paduan utamanya. Baja dapat diklasifikasikan dalam dua kelompok besar yaitu baja karbon dan baja paduan. Baja karbon adalah baja yang tidak mengandung unsur-unsur paduan, jadi unsur yang dipakai adalah karbon (C) atau Baja karbon adalah baja yang dimana karbon sebagai unsur yang utama dalam menentukan sifatsifat dari baja. Sedangkan baja paduan adalah baja dengan banyak unsur paduan seperti : karbon (C), kromium (Cr), silicon (Si), nikel (Ni), molibdenum (Mo), wolfram (W), dan vanadium (V). Unsurunsur ini dibatasi dalam kandungan tertentu dengan tujuan agar memperoleh kekuatan baja sesuai dengan kebutuhan. Kekuatan baja yang diinginkan adalah kekuatan secara mekanik dan kimia. Yang dimaksud dengan kekuatan kimia adalah kekuatan baja terhadap korosi, sedangkan korosi sendiri adalah merupakan peristiwa penurunan kualitas logam akibat pengaruh lingkungan yang bersifat asam, basa, dan bahan kimia lainnya. Oleh karena itu sebelum baja digunakan, Sebaiknya mengetahui sifat-sifat mekanik dn sifatsifat yang lain, misalnya sifat kimia dari baja.

Ditinjau dari kandungan karbonnya, baja karbon digolongkan menjadi 3 macam, yaitu :

1. baja karbon rendah $(<0,3 \%)$,

2. baja karbon sedang $(0,3 \%-0,6 \%)$,

3. dan baja karbon tinggi $(>0,6 \%)$.

Baja karbon sedang memiliki kekuatan dan kekerasan yang lebih tinggi dari baja karbon rendah, serta mempunyai keuletan yang lebih tinggi dari baja karbon tinggi. Oleh karena itu baja karbon sedang biasanya digunakan untuk membuat peralatan mesin seperti roda gigi dan pinion, sekrup sungkup, as, spindle mesin perkakas, baut, pipa sepeda, pasak, dan laras senapan.

Namun karena diproduksi secara massal maka baja yang terdapat dipasaran atau yang tersedia biasanya kurang cocok apabila kita menginginkan kekuatan baja yang lebih spesifik untuk membuat konstruksi tertentu. Dengan kata lain apabila dibutuhkan kekuatan dan keuletan tertentu untuk digunakan sebagai komponen khusus pada suatu konstruksi maka diperlukan proses untuk meningkatkan kekuatan dan keuletan serta ketahanan korosi pada baja tersebut. Maka perlu dilakukan Heat Treatment atau perlakuan panas pada baja tersebut. Dengan cara ini dapat meningkatkan kekuatan mekanik baja, peningkatan ini juga diikuti dengan perubahan secara fisis dari baja.

Tujuan dari heat treatment adalah untuk peningkatan keliatan bahan, penghilangan tegangan dalam, penghalusan ukuran butiran, dan meningkatkan kekerasan atau tegangan tarik serta merubah struktur mikro permukaan logam (Rajan, dkk. 1997). Heat treatment yang dapat dilakukan pada baja karbon adalah perlakuan panas fisis, seperti hardening dan tempering. Rajan, dkk. (1997) mengemukakan bahwa sifat-sifat dari baja (kekuatan, kekerasan dan ketangguhan) dari proses pengerasan (quenching) tergantung dari barbagai faktor diantaranya suhu austenit, waktu tahan, dan media pendingin.

Dalam penelitian ini menggunakan bahan Baja paduan AISI 420 yang termasuk kedalam golongan baja karbon sedang. Baja karbon sedang mempunyai kekuatan dan ketangguhan yang baik dan respon perlakuan panas yang bagus. Sehingga akan menunjukkan hasil yang cukup signifikan antara sebelum diberikan heat treatment dan sesudah dilakukan heat treatment. Baja paduan AISI 420 Diproduksi oleh LUCCHINI yang merupakan perusahaan pengolahan baja yang berasal dari Negara Italia, sedangkan di Indonesia didistribusikan lewat PT. GENTA LARAS SEMESTA. Berdasarkan 
standar AISI (American Iron and Steel Institute) baja ini termasuk dalam grade 420, yaitu golongan martensitic stainless steel.

Karena sifat baja karbon sedang yang cukup tangguh dan ulet serta ketahanan terhadap aus tinggi, maka baja karbon sedang sangat banyak digunakan dalam otomotif maupun konstruksi yang mengalami beban dinamis serta kebutuhan proses permesinan yang membutuhkan bahan dengan ketahanan korosi yang tinggi. Berikut disajikan pada Tabel 1 adalah penamaan Baja AISI 420 secara internasional :

Tabel 1. Nama AISI 420 secara internasional

\begin{tabular}{|c|c|c|}
\hline ORGANISASI & NOMOR KODE & NEGARA \\
\hline JIS & SUS 420 J2 & Jepang \\
\hline W. Nr. & 1.2316 & Jerman \\
\hline DIN & X38CrMo16.1 KU & Jerman \\
\hline AISI & 420F & Amerika Serikat \\
\hline
\end{tabular}

Baja AISI 420 Secara umum kandungan kimianya adalah sebagai berikut pada Tabel 2

Tabel 2. Kandungan Kimia Baja AISI 420 secara umum

\begin{tabular}{|c|c|c|c|c|c|}
\hline $\mathrm{C}$ & $\mathrm{Cr}$ & $\mathrm{Mo}$ & $\mathrm{Ni}$ & $\mathrm{Mn}$ & $\mathrm{Si}$ \\
\hline \begin{tabular}{c|c|c|c|c|}
\hline 0,33 \\
-
\end{tabular} & $15,00-$ & $1,00-$ & $<1,00$ & $<1,00$ & $<1,00$ \\
0,43 & 17,50 & 1,30 & & & \\
\hline
\end{tabular}

Paduan unsur crom merupakan unsur yang mempengaruhi logam dalam ketahanan terhadap korosi. Resistensi terhadap korosi yang tinggi pada baja ini disebabkan oleh kandungan unsur $\mathrm{Cr}$ yang cukup dominan, Baja ini tersedia di pasaran dalam kondisi yang telah mengalami proses annealing sehingga mempunyai tingkat kekerasan $\leq 250$ HB. Karena tersedia dalam kondisi anealled maka baja ini memiliki mampu mesin yang baik sehingga dapat dibentuk sesuai dengan bentuk yang dibutuhkan tanpa mengalami keretakan atau tegangan sisa yang berarti sehingga material tidak mengalami kerusakan baru kemudian dilakukan heat threatment sesuai dengan kebutuhan. Berikut adalah kekuatan Fisik dari baja AISI 420 disajikan oleh Tabel 3.

Tabel 3. Kekuatan Fisik Baja AISI 420

\begin{tabular}{|c|c|c|c|}
\hline Temperatur & $20^{\circ} \mathrm{C}$ & $250^{\circ} \mathrm{C}$ & $500^{\circ} \mathrm{C}$ \\
\hline $\begin{array}{l}\text { Modulus Elastisitas } \\
\left(\mathrm{kN} / \mathrm{mm}^{2}\right)\end{array}$ & 210 & 198 & 177 \\
\hline $\begin{array}{l}\text { Koefisien Ekspansi } \\
\text { Thermal }\left(10^{-6} / 0 \mathrm{~K}\right)\end{array}$ & - & 11,4 & 12,2 \\
\hline $\begin{array}{l}\text { Konduktivitas Thermal } \\
\text { (W/Mk) }\end{array}$ & 17,5 & 20,7 & 23,2 \\
\hline
\end{tabular}

\section{METODE PENELITIAN}

\section{A. Alat Penelitian}

1. Untuk pembuatan spesimen digunakan mesin - mesin perkakas sebagai berikut :

a). Mesin bubut

b). Mesin gergaji

2. Dapur Pemanas Listrik

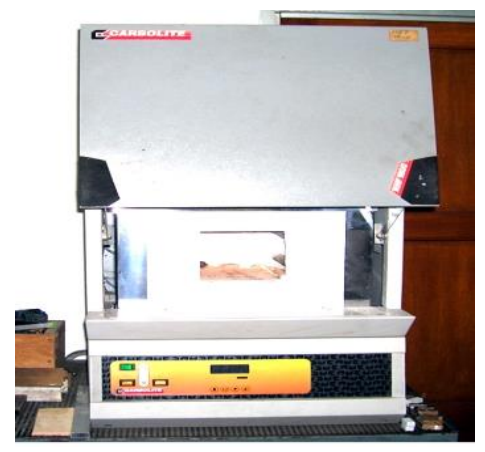

Gambar 1. Dapur pemanas

3. Alat uji komposisi bahan

Tempat : Laboratorium PT. Karya Hidup Sentosa (KHS), Jl. Magelang Jatimulyo, Yogyakarta

4. Alat uji korosi (tipe sel tiga elektroda) 
Tempat : Laboratorium Badan Tenaga Atom Nasional (BATAN), Jl. Babarsari, Yogyakarta

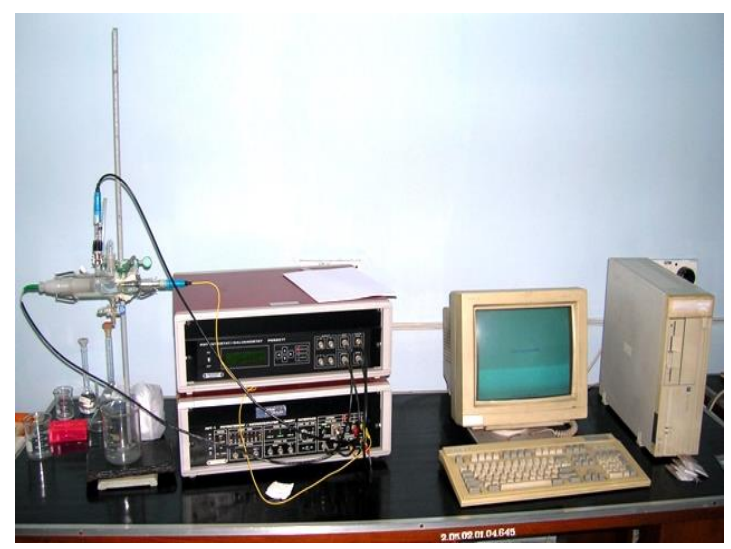

Gambar 2. Alat uji korosi Potensial/Galvanostat PGS 201T

5. Mikroskop untuk uji metalografi (struktur mikro)

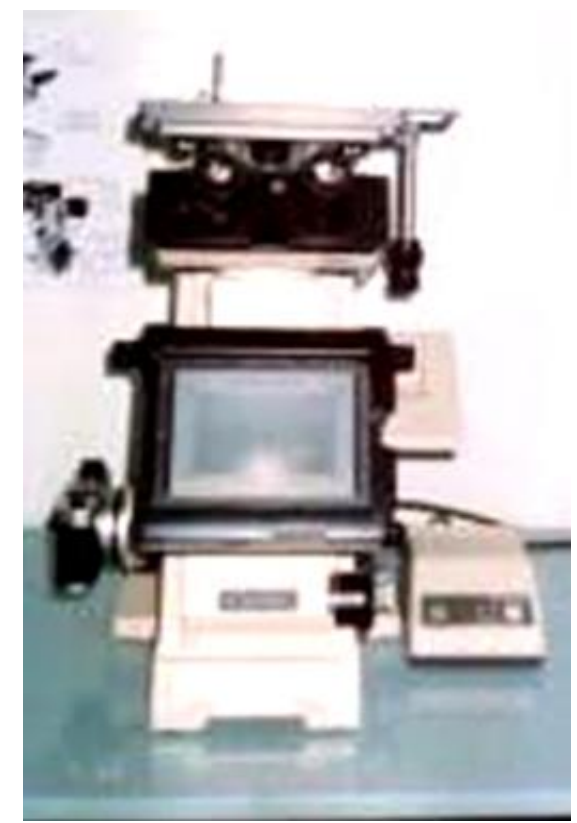

Gambar 3. Alat uji struktur mikro

6. Alat uji kekerasan Micro Vickers

Penelitian ini menggunakan beberapa alat uji dengan spesifikasi sebagai berikut :

1. Alat uji korosi

Nama alat uji

Potensiostat/Galvanostat

Model

: PGS 201T
Rentang tegangan

: $-2000 \mathrm{mV}$

sampai dengan $2000 \mathrm{mV}$

Rentang arus

: $200 \mathrm{nA}$

sampai dengan $2 \mathrm{~A}$

Diproduksi oleh

: Tacussel

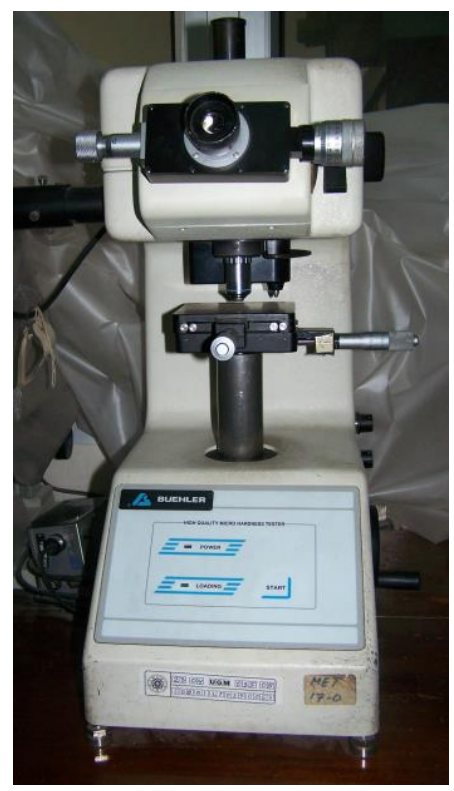

Gambar 4. Alat uji Micro Hardness Tester

2. Alat Uji Metalografi

Nama alat uji

Logam Olympus

Model

: Mikroskop

3. Alat uji kekerasan

Nama alat uji

: PME 3

Hardness Tester

Merk

German.

Beban indentasi $\quad: 1 \mathrm{~kg}$

Waktu pembebanan : Otomatis

\section{B. Bahan Penelitian}

Bahan yang dipakai dalam penelitian ini adalah AISI 420. Dalam standar AISI bahan ini termasuk dalam stainless steel grade 420F. Baja ini termasuk dalam golongan baja tahan karat martensitik yang memiliki resistensi terhadap korosi.

Dimensi spesimen yang digunakan untuk penelitian ini mengambil acuan ukuran spesimen standar untuk pengujian korosi dari pihak P3TM Batan, kemudian untuk mempermudah dan mempersingkat 
waktu pembuatan spesimen untuk pengujian yang lainnya seperti uji Metalografi dan uji kekerasan Vickers maka digunakan ukuran dan dimensi spesimen yang sama dengan yang dipakai pada pengujian korosi yaitu adalah sebagai berikut :

1. Dimensi spesimen silinder / koin : a). diameter $13 \mathrm{~mm}$ dengan tebal $3 \mathrm{~mm}$

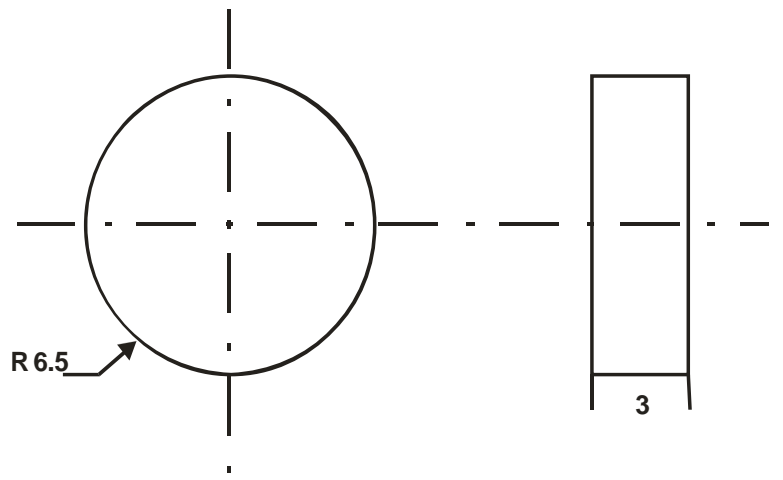

Gambar 5. Spesimen silinder / koin

\section{HASIL DAN PEMBAHASAN}

\section{A. Hasil}

\section{1) Uji Komposisi Kimia}

Pengujian uji komposisi pada bahan raw material atau bahan dasar baja paduan AISI 420 dilakukan di Pt. Karya Hidup Sentosa (KHS).Hasil pengujian komposisi kimia bahan spesimen baja AISI 420 (bahan dasar) didapat unsur - unsur yang terkandung dalam baja tersebut. Dalam prosentase berat unsur - unsur yang terkandung dalam baja AISI 420 adalah sebagai berikut pada Tabel 4 :

Tabel 4. Komposisi Kimia Baja AISI 420

\begin{tabular}{|c|c|}
\hline NAMA UNSUR & JUMLAH (\%) \\
\hline $\mathrm{C}$ & 0,3583 \\
\hline $\mathrm{Si}$ & 0,2800 \\
\hline $\mathrm{S}$ & 0,0040 \\
\hline $\mathrm{P}$ & 0,0210 \\
\hline $\mathrm{Mn}$ & 0,8199 \\
\hline $\mathrm{Ni}$ & 0,4879 \\
\hline $\mathrm{Cr}$ & 18,7597 \\
\hline $\mathrm{Mo}$ & 0,8549 \\
\hline $\mathrm{Cu}$ & 0,1489 \\
\hline $\mathrm{W}$ & 0,0196 \\
\hline $\mathrm{Ti}$ & 0,0035 \\
\hline
\end{tabular}

\begin{tabular}{|c|c|}
\hline $\mathrm{Sn}$ & 0,0093 \\
\hline $\mathrm{Al}$ & 0,0426 \\
\hline $\mathrm{Pb}$ & 0,0000 \\
\hline $\mathrm{Ca}$ & 0,0051 \\
\hline $\mathrm{Zn}$ & 0,0218 \\
\hline $\mathrm{Fe}$ & 78,16 \\
\hline
\end{tabular}

Hasil pengujian komposisi ini didapatkan data pada tabel diatas dengan kandungan unsur - unsur dan prosentase beratnya yang mendekati dengan kandungan unsur - unsur serta prosentase berat pada referensibaja AISI 420.Data uji komposisi dapat digunakan untuk melihat apakah suatu logam cukup responsif untuk diperlakukan panas atau tidak serta kemungkinan pengaruh perlakuan panas tersebut terhadap laju korosi.Baja AISI 420 ini masuk dalam golongan martensitic stainless steel atau baja tahan karat martensitik, dengan kandungan kromium yang cukup besar yaitu 18\%.Martensitic stainless steeldengan kandungan karbon sedang dikembangkan untuk paduan baja tahan karat yang bisa dikeraskan oleh perlakuan panas.Sehingga tipe martensitik ini digunakan untuk kebutuhan yang memerlukan kekerasan (hardness), kekuatan (strength) dan ketahanan pakai (thoughness).

\section{2) Uji Kekerasan}

Uji kekerasan penelitian ini dilakukan pengujian sebanyak lima titik yang diaplikasikan pada spesimen Raw material dan spesimen yang mengalami perlakuan panas. Lima titik tersebut dimulai dari tepi spesimen menuju ketengah. Hal tersebut dilakukan agar didapatkan data yang akurat, dan dapat mewakili atau dapat menunjukkan nilai kekerasan sebenarnya tiap spesimen baik yang mengalami perlakuan panas atau sebelum mengalami perlakuan panas. Kekerasan logam menunjukkan tolok ukur ketahanannya terhadap deformasi plastik atau deformasi permanen. Setelah dilakukan pengujian kekerasan diperoleh data hasil uji kekerasan dari baja AISI 420 pada Tabel 5. 
Tabel 5. Hasil Uji Kekerasan

\begin{tabular}{|l|l|c|c|}
\hline No & SPESIMEN & $\begin{array}{c}\text { TEMPERATUR } \\
\left({ }^{\circ} \mathrm{C}\right)\end{array}$ & $\begin{array}{c}\text { VHN } \\
\left(\mathrm{kg} / \mathrm{mm}^{2}\right)\end{array}$ \\
\hline 1 & $\begin{array}{l}\text { Raw } \\
\text { Material }\end{array}$ & - & 288 \\
\hline 2 & $\begin{array}{l}\text { Quenching, } \\
1 \text { jam }\end{array}$ & $\mathrm{T}=1020{ }^{\circ} \mathrm{C}$ & 551 \\
\hline 3 & $\begin{array}{l}\text { Tempering, } \\
45 \text { menit }\end{array}$ & $\mathrm{T}=200{ }^{\circ} \mathrm{C}$ & 430 \\
\hline 4 & $\begin{array}{l}\text { Tempering, } \\
45 \text { menit }\end{array}$ & $\mathrm{T}=300{ }^{\circ} \mathrm{C}$ & 405 \\
\hline
\end{tabular}

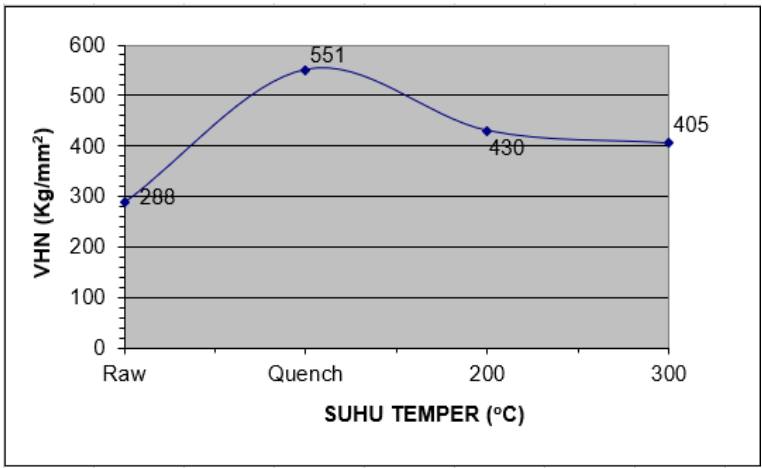

Gambar 6. Grafik hasil uji kekerasan

Sesuai dengan data pada Tabel 5 tersebut, baja ini memiliki nilai kekerasan awal sebelum mengalami perlakuan panas sebesar $288 \mathrm{~kg} / \mathrm{mm}^{2}$ ini terbaca pada spesimen raw material atau spesimen bahan dasar.Setelah diliakukan heat treatment spesimen yang memiliki nilai kekerasan tertinggi adalah spesimen yang mengalami quenching, yaitu dengan nilai $551 \mathrm{~kg} / \mathrm{mm}^{2}$. Nilai yang terbaca cukup jauh perbedaannya dan itu menunjukkan pengaruh quenching pada baja AISI 420. Kemudian nilai terendah terlihat pada spesimen yang mengalami tempering pada suhu $300^{\circ} \mathrm{C}$ yaitu dengan nilai kekerasan sebesar $405 \mathrm{~kg} / \mathrm{mm}^{2}$.

Dengan nilai kekerasan sebesar $551 \mathrm{~kg} / \mathrm{mm}^{2}$ proses quenching pada penelitian ini meningkatkan nilai kekerasan hingga sebesar $47,73 \%$ dengan acuan nilai kekerasan pada bahan dasarnya. Tingkat kekerasan pada spesimen tempering $300^{\circ} \mathrm{C}$ ini rendah karena terbentuknya karbida dengan dimensi yang besar disebut dengan speroidit. Karbida yang terbentuk merupakan dispersi partikel yang bulat dalam matriks ferit. Dengan proses penemperan yang agak lama partikel karbida yang terbentuk dapat bersatu membentuk partikel karbida dengan dimensi yang lebih besar yang dinamakan speroidit.Partikel karbida yang keras dapat menghambat deformasi plastik matriks ferit yang lunak dan ulet, besar hambatan ini berbanding lurus dengan kontak antara kedua fasa tersebut, yaitu batas fasa antara ferit dan karbida persatuan volume.

Hal ini menunjukkan bahwa speroidit atau terbentuknya karbida dengan dimensi yang besar mengakibatkan penurunan tingkat kekerasan. Namun dari segi tingkat resistensi terhadap korosi, situasi ini dapat mencegah terjadinya korosi karena terjadi pengurangan daerah batas butir, dimana dapat terjadi presipitasi karbida pada daerah batas butir ini yang akan menyebabkan terjadinya korosi intergranuler.

\section{3) Uji Korosi}

Pengujian korosi ini dilakukan di Laboratorium korosi P3TM BATAN Yogyakarta dengan menggunakan alat uji korosi potensiostat / galvanostat PGS 201T milik P3TM BATAN Yogyakarta. Pengujian menggunakan medium elektrolit berupa larutan asam klorida atau $\mathrm{HCl}$ dengan konsentrasi 0,01 M. Dipilih menggunakan media larutan elektrolit dengan larutan $\mathrm{HCl}$ dengan konsentrasi 0,01 M. Uji korosi dilakukan pada spesimen baja AISI 420 sebelum perlakuan panas dan setelah perlakuan panas.

Hasil pengujian korosi ini didapat berupa grafik tafel untuk masing-masing spesimen. Kurva polarisasi pada grafik tafel ini menunjukkan hubungan potensial $(E)$ dalam satuan $\mathrm{mV}$ sebagai fungsi $\log$ arus (I) dalam satuan $\left(\mu A / \mathrm{cm}^{2}\right)$. Kurva polarisasi ini menginformasikan reaksi oksidasi dan reaksi reduksi pada elektroda kerja (spesimen yang diuji). Yang kita tahu 
bahwa pada saat reaksi oksidasi ini maka terjadi peristiwa pelepasan elektron kemudian pada reaksi reduksi adalah reaksi yang membutuhkan atau menerima elektron. Potensial korosi bisa diukur ketika elektroda kerja bernilai arus nol dan rapat arus korosi $I_{k o r}$ akan terukur dengan ekstrapolasi tafel dari kurva polarisasi.

Nilai rapat arus korosi memperlihatkan banyak atau sedikitnya jumlah ion-ion logam yang larut dalam larutan elektrolit atau media yang dipakai dalam pengujian.Dengan demikian hal itu akan menunjukkan bahwa logam mengalami reaksi oksidasi, yang dimana terjadi pelepasan elektron yang mengakibatkan ion-ion positif logam akan larut dalam larutan elektrolit. Apabila rapat arus yang terbaca besar dapat disimpulkan bahwa ion-ion logam banyak yang larut ke dalam larutan elektrolit. Hal itu akan membuat kondisi logam berada tidak stabil, seperti kondisi logam pada awalnya yang akan mengarah pada terjadinya kerusakan pada bagian permukaannya karena bereaksi dengan lingkungannya.

Dengan menggunakan besarnya rapat arus korosi $I_{k o r}$ yang terbaca pada data yang terdapat pada grafik tafel maka dapat dihitung laju korosi dari masing-masing spesimen. Dalam penelitian laju korosi dengan menggunakan metode elektrolisis diorientasikan bahwa laju korosi merupakan kedalaman korosi pada suatu bahan dalam waktu tertentu, atau dimaknakan bahwa laju korosi merupakan kecepatan bahan untuk mengalami korosi.

Data hasil pengujian korosi yang telah dilakukan pada baja AISI 420 meliputi rapat arus korosi serta hasil perhitungan berupa laju korosinya terdapat pada Tabel 6.

Setelah melakukan analisa pada data hasil pengujian korosi dan hasil perhitungan laju korosinya maka dapat dilihat bahwa semakin kecil rapat arus korosinya maka hal itu menunjukkan laju korosinya rendah maka memiliki resistensi yang tinggi terhadap korosi. Kemudian apabila rapat arus korosinya makin besar menunjukkan bahwa laju korosi makin besar yang memperlihatkan bahwa ketahanan terhadap korosinya semakin rendah, sehingga akan cepat terkena korosi.

Tabel 6. Data rapat arus dan laju korosi

\begin{tabular}{|c|c|c|c|c|c|c|}
\hline \multicolumn{2}{|c|}{$\begin{array}{c}\text { SPESIMEN } \\
\text { (2 spesimen / pengujian) }\end{array}$} & \multirow{2}{*}{$\begin{array}{c}\mathrm{E} \\
(\mathrm{I}=0) \\
(m V) \\
-562,5\end{array}$} & \multirow{2}{*}{\begin{tabular}{|c}
$\begin{array}{c}\text { RAPAT } \\
\text { ARUS } \\
\text { KOROSI }\end{array}$ \\
$\left(I_{\text {cor }}\right)$ \\
$\left(\mu \mathrm{A} / \mathrm{cm}^{2}\right)$ \\
56,66
\end{tabular}} & \multirow{2}{*}{\begin{tabular}{|c} 
LAJU \\
KOROSI \\
(mpy)
\end{tabular}} & $\begin{array}{l}\text { LAJU } \\
\text { KOROSI } \\
\text { Rata- } \\
\text { rata }(m p \\
y)\end{array}$ & \multirow{2}{*}{\begin{tabular}{|c} 
LAJU \\
KOROSI \\
$(\mathrm{mm} / \mathrm{y})$ \\
\\
\end{tabular}} \\
\hline RAW & & & & & \multirow[b]{2}{*}{22,385} & \\
\hline MATERIAL & $\begin{array}{l}\text { Danan } \\
\text { dasar }\end{array}$ & $-564,7$ & 53,33 & 21,707 & & 0,569 \\
\hline \multirow{2}{*}{ QUENCHING } & \multirow{2}{*}{$\begin{array}{l}\mathrm{T}= \\
1020^{\circ} \mathrm{C} \\
1 \mathrm{Jam}\end{array}$} & $-421,2$ & 22,73 & 9,252 & \multirow{2}{*}{10,524} & \multirow{2}{*}{0,267} \\
\hline & & $-308,0$ & 29,47 & 11,995 & & \\
\hline \multirow{4}{*}{ TEMPERING } & \multirow{2}{*}{$\begin{array}{l}\mathrm{T} 1= \\
200^{\circ} \mathrm{C} \\
45 \text { menit }\end{array}$} & $-485,4$ & 29,62 & 12,056 & \multirow{2}{*}{17,724} & \multirow{2}{*}{0,450} \\
\hline & & $-532,7$ & 57,47 & 23,392 & & \\
\hline & \multirow{2}{*}{$\begin{array}{l}\mathrm{T} 2= \\
300^{\circ} \mathrm{C} \\
45 \text { menit }\end{array}$} & $-565,1$ & 18,56 & 7,554 & \multirow[b]{2}{*}{12,254} & \multirow[b]{2}{*}{0,311} \\
\hline & & $-540,6$ & 41,65 & 16,953 & & \\
\hline
\end{tabular}

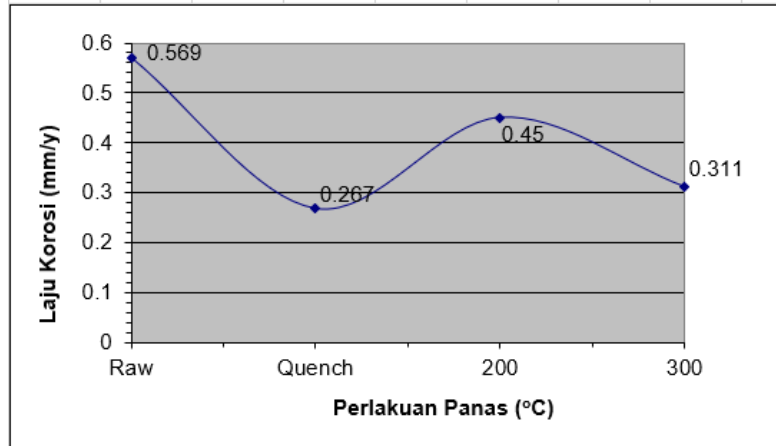

Gambar 7. Grafik Laju Korosi

Apabila dilihat dari variasi perlakuan panasnya, bahan yang memiliki resistensi korosi paling rendah terjadi pada spesimen bahan dasar. Artinya bahan ini akan mengalami korosi paling cepat dibandingkan dengan spesimen lainnya yang mengalami perlakuan panas. Spesimen yang mengalami quenching menunjukkan penurunan laju korosi atau mengalami peningkatan resistensi terhadap korosi cukup signifikan dibandingkan dengan spesimen bahan dasar. Kemudian pada penelitian ini bahan yang mengalami laju korosi paling rendah terjadi pada 
spesimen yang mengalami perlakuan panas tempering pada suhu $400^{\circ} \mathrm{C}$.

Laju korosi yang terhitung pada spesimen yang mengalami tempering pada suhu $300^{\circ} \mathrm{C}$ sebesar $0,311 \mathrm{~mm} / \mathrm{y}$. Pada spesimen yang telah mengalami proses perlakuan panas laju korosi yang paling tinggi terdapat pada spesimen yang mengalami proses tempering pada suhu $200^{\circ} \mathrm{C}$ yaitu dengan nilai laju korosi sebesar $0,450 \mathrm{~mm} / \mathrm{y}$.

Heat treatment yang dilakukan pada baja ini dapat mempengaruhi laju korosi yang terjadi dengan berubahnya struktur mikro dari logam. Sebelum proses penemperan baja mengandung satu fasa yang dominan yaitu fasa martensit yang mempunyai struktur tetragonal pemusatan ruang. Kemudian saat proses penemperan martensit akan bertransformasi menjadi ferit $(\alpha)$ dan karbida karena akibat dari pendinginan yang cukup lama karena menggunakan media udara sebagai pendinginnya. Pada saat ferit dan karbida terbentuk maka akan membuat batas-batas butir dari ferit dan karbida semakin banyak yang dapat berakibat lebih cepat terjadinya laju korosi. Itu terjadi pada awal penemperan dengan suhu yang rendah. Hal ini terjadi pada penelitiann ini untuk suhu temper $200^{\circ} \mathrm{C}$ yang menunjukkan laju korosi terbesar diantara perlakuan panas yang lainnya. Namun saat penemperan pada suhu yang lebih tinggi pada $300^{\circ} \mathrm{C}$ karbida-karbida yang tersebar akan mengumpul kembali, hal ini membuat jumlah batas butir dari ferit dan karbida akan berkurang yang otomatis laju korosinya juga akan berkurang.

Fenomena yang terjadi pada laju korosi yang besar pada suhu temper $200^{\circ} \mathrm{C}$ tersebut terjadi pada baja AISI 420 dan juga kebanyakan baja tahan karat martensitik 420f. Hal tersebut dikarenakan terjadinya pengendapan atau presipitasi karbida di batas-batas butir sehingga butiran yang berdekatan kekurangan kromium. Apabila kromium pada batas butir berkurang maka di daerah tersebut akan mudah terserang korosi.

Dari data pada tabel 6 maka dapat dibahas bahwa spesimen yang mengalami quenching pada suhu $1020^{\circ} \mathrm{C}$ mengalami penurunan laju korosi yang cukup signifikan dilihat dari arus laju korosi yang rendah.

Hasil data penelitian ini memperlihatkan bahwa setelah dilakukan proses heat treatment terhadap baja AISI 420 dapat meningkatkan ketahanannya terhadap serangan korosi.

\section{4) Uji Metalografi}

Pengujian struktur mikro dilakukan pada setiap spesimen yang belum mengalami perlakuan panas maupun yang sudah mengalami perlakuan panas. Uji metalografi digunakan untuk mengambil foto-foto struktur mikro dari spesimen baja AISI 420.Masing - masing spesimen seharusnya memiliki struktur mikro yang berbeda karena tiap spesimen dilakukan heat treatment yang berbeda yaitu dengan proses quenching dan proses tempering dengan beberapa variasi suhu temper. Tiap spesimen dicari suatu daerah pemotretan yang bersih dan paling jelas terlihat struktur mikronya. Dan kemudian tiap spesimen difoto sebanyak satu kali. Spesimen yang dipakai dalam uji metalografi ini ada 4 spesimen yaitu spesimen bahan dasar, spesimen quenching pada suhu $1020^{\circ} \mathrm{C}$ dan spesimen quenching-tempering dengan variasi suhu temper $200^{\circ} \mathrm{C}$ dan $300^{\circ} \mathrm{C}$.

Pengambilan foto struktur mikro spesimen dilakukan dengan perbesaran 200x.Yang juga perlu diperhatikan adalah pada saat pengambilan foto, spesimen harus rata dan bersih. Hal tersebut perlu diperhatikanagar strukturnya terlihat dengan jelas. Alat uji yang dipakai untuk pemotretan ini menggunakan Mikroskop Logam dengan merek Olympus.

Berikut foto - foto hasil uji metalografi dengan menggunakan perbesaran 200x : 
1. Struktur mikro pada raw material

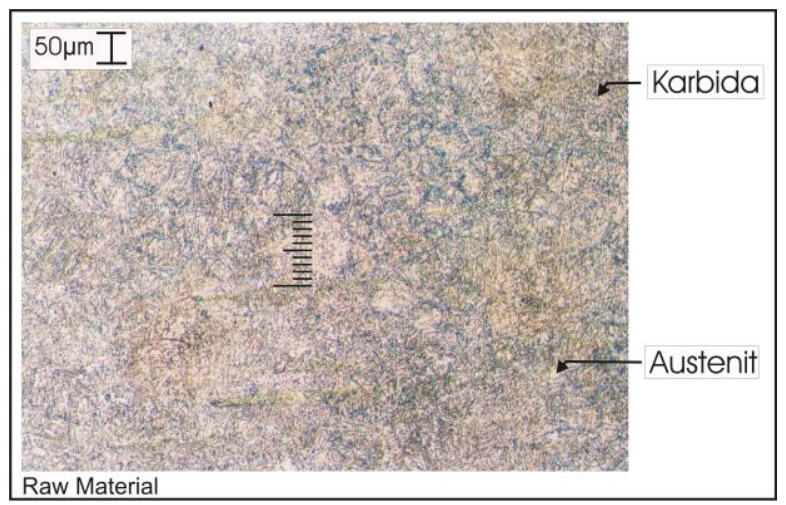

Gambar 8. Struktur mikro baja AISI 420sebelum perlakuan panas (bahan dasar/raw material) dengan perbesaran 200x

2. Struktur Mikro spesimen quenching

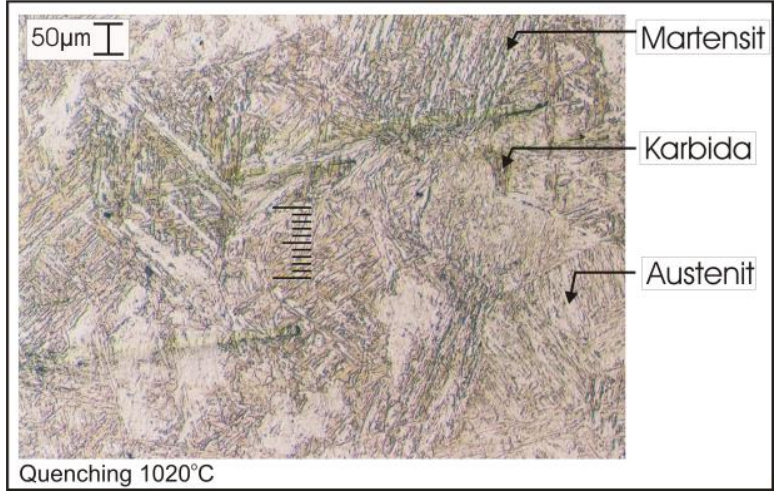

Gambar 9. Struktur mikro baja AISI 420 dengan proses quenchingpada suhu $1020^{\circ} \mathrm{C}$ selama satu jam pada media pendingin oli dengan perbesaran 200x

3. Struktur Mikro Spesimen Quenching Tempering $200^{\circ} \mathrm{C}$

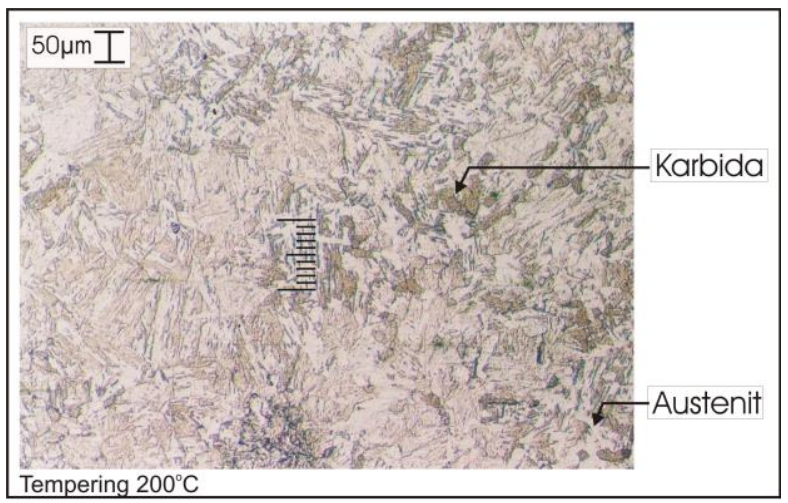

Gambar 10. Struktur mikro baja AISI 420 dengan proses temperingpada suhu $\mathbf{2 0 0}^{0} \mathrm{C}$ selama 45 menit.

4. Struktur Mikro Spesimen Quenching Tempering $300^{\circ} \mathrm{C}$

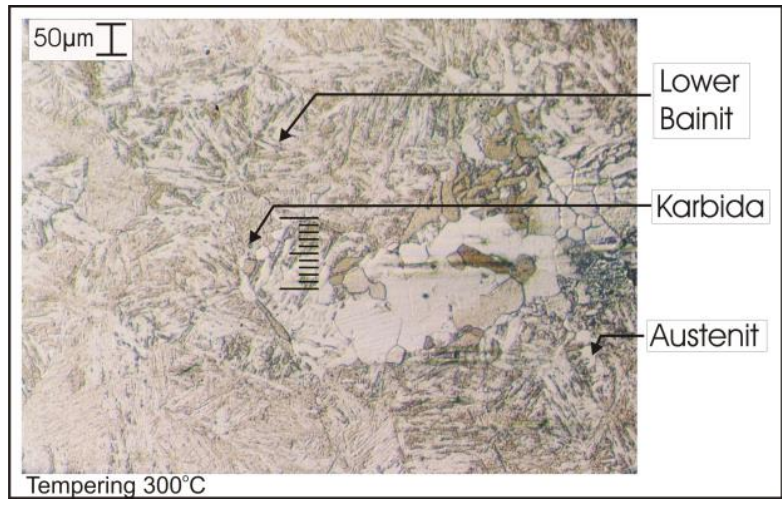

Gambar 11. Struktur mikro baja AISI 420 dengan proses tempering pada suhu $\mathbf{3 0 0}^{0} \mathrm{C}$ selama 45 menit.

Baja AISI 420 yang dipakai dalam penelitian ini adalah yang sudah mengalami proses anealing dari pabriknya. Dan hal ini ditunjukkan dari struktur mikro spesimen bahan dasarnya yang menunjukkan matriks ferit dengan karbida yang terdispersi secara merata pada butir logam. Kemudian pada spesimen dengan proses quenching didominasi oleh fasa martensit, dan austenit sisa namun juga terdapat karbida.Austenit sisa tersebut dapat terbentuk karena pada baja ini mengandung komposisi karbon sebesar 0,358\%, namun apabila kadar karbon yang terdapat pada baja lebih dari $0,5 \%$ maka akan lebih banyak austenit sisa yang terbentuk dan dapat mengakibatkan turunnya temperatur pembentukan martensit.

Untuk baja paduan yang termasuk dalam martensitic stainless steel Pada saat quenching dilakukan maka saat proses pendinginan terjadi, Austenit akan bertransformasi menjadi Martensit. Transformasi Austenit menjadi Martensit ini terjadi pada rentang suhu antara $300^{\circ} \mathrm{C}$ $700^{\circ} \mathrm{C}$ dan akan berhenti bertransformasi 
pada suhu sekitar $150^{\circ} \mathrm{C}-200^{\circ} \mathrm{C}$ dibawah rentang suhu saat terjadi transformasi.

Heat treatment yang dilakukan pada penelitian ini adalah quenching dan tempering, oleh karena itu setelah semua spesimen dilakukan quenching, maka selanjutnya beberapa spesimen dilakukan penemperan dengan variasi suhu temper $200^{\circ} \mathrm{C}$ dan $300^{\circ}$ C.Di suhu temper $200^{\circ} \mathrm{C}$ karbon akan keluar dari larutan yang biasanya sebagai karbida kaya kromium $\left(\mathrm{Cr}_{23} \mathrm{C}_{6}\right)$. Presipitasi karbida pada batas butir ferit ini bahkan bisa terjadi ketika kandungan karbon pada baja sangat rendah sekalipun yaitu misalnya $<0,05 \%$.Presipitasi yang terjadi pada baja yang dikenakan perlakuan panas ini bisa mengakibatkan terjadinya deplesi dari daerah-daerah yang berdekatan dengan batas-batas butir berhubungan dengan kadar kromium. Atau dengan kata lain akan mengakibatkan daerah tersebut menjadi kekurangan kromium sehingga berdampak pada lebih mudah terserang korosi yang disini adalah awal mula korosi intergranular. Semetara disisi lain presipitasi karbida ini menimbulkan efek merugikan dalam sifat mekaniknya, khususnya sifat liat pada temperatur rendah.

Hasil uji metalografi untuk proses tempering dengan suhu $300^{\circ} \mathrm{C}$ menggambarkan bahwa karbida yang terbentuk semakin banyak. Hal ini terjadi seiring dengan naiknya suhu temper.Produk heat treatment seperti bainit mulai terbentuk akibat dari austenit sisa yang terurai, bentuknya menyerupai tempered martensit atau martensit temper tetapi dengan bentuk yang agak sedikit lebih kotak-kotak dan tidak terlalu meruncing.Suhu temper disini $300^{\circ} \mathrm{C}$ dan masih tergolong suhu rendah untuk pembentukan bainit, oleh karenanya bainit yang terbentuk disebut dengan lower bainit. Bainit terbentuk atau bertransformasi pada rentang suhu sekitar $300^{\circ} \mathrm{C}-400^{\circ} \mathrm{C}$ dengan transformasi sampai komplet dan akan lebih cepat terbentuk pada rentang suhu sekitar $400^{\circ} \mathrm{C}-500^{\circ} \mathrm{C}$ namun proses transformasinya tidak komplet.

\section{KESIMPULAN}

Setelah melakukan analisa dan pembahasan hasil penelitian ini maka dalam penelitian ini dapat diambil kesimpulan sebagai berikut :

1. Kekerasan bahan meningkat setelah heat treatment. Nilai kekerasan tertinggi adalah spesimen yang telah mengalami quenching dengan nilai kekerasan 551 $\mathrm{kg} / \mathrm{mm}^{2}$. Hal ini sangat jauh nilainya jika dibandingkan dengan spesimen bahan dasar, dimana spesimen ini memiliki nilai kekerasan sebesar 288 $\mathrm{kg} / \mathrm{mm}^{2}$.

2. Nilai kekerasan terendah terdapat pada spesimen yang mengalami proses tempering pada suhu $300^{\circ} \mathrm{C}$, dengan nilai kekerasan $405 \mathrm{~kg} / \mathrm{mm}^{2}$. Menurunnya kekerasan spesimen ini terjadi karena terbentuknya karbida dengan dimensi yang besar dan dinamakan speroidit.

3. Spesimen raw material atau bahan dasar laju korosinya sebesar $0,569 \mathrm{~mm} / \mathrm{y}$, spesimen dengan perlakuanquenching terjadi penurunan laju korosi yang cukup signifikan yaitu sebesar $0,267 \mathrm{~mm} / \mathrm{y}$. Dan kemudian ketika dilakukan temperinglaju korosi tetap lebih rendah dibandingkan dengan laju korosi pada bahan dasar yaitu pada suhu temper $200^{\circ} \mathrm{C}$ laju korosinya $0,450 \mathrm{~mm} / \mathrm{y}$ dan suhu temper $300^{\circ} \mathrm{C}$ laju korosinya $0,311 \mathrm{~mm} / \mathrm{y}$

Data-data ini menunjukkan bahwa proses heat treatment terhadap baja AISI 420 dapat meningkatkan ketahanan terhadap korosi.

\section{DAFTAR PUSTAKA}

ASM, 1989, Metals Handbook Metallographyand Microstructures, Vol. 9, Ninth Edition, Gulf Publishing Company, Houston. 
Honey Combe, R.W.K and Bhadeshia, H.K.D.H, Steel Microstructure and properties, Second Edition, Edward Arnold, London.

Jones, D.A.,1991, Principles and Pevention of Corrosion, Macmillan Publishing Company, New York.

Kenneth R. Trethewey., John Chamberlain., Korosi untuk Mahasiswa Sains dan Rekayasa., PT. Gramedia Pustaka Pratama, Jakarta.

Mars G. Fontana., 1987, Corrosion Engineering., Third Edition, McGraw-Hill Book Company, New York

Pierre R. Roberge 2000, Handbook of Corrosion Engineering, McGrawHill Companies, Inc.

Rajan, T. V., Sharma, C. P., and Sharma Ashok., 1997, Heat Treatment : Principles andTechniques, Prentice Hall of India, New Delhi.

Rochim Suratman, 1994, Panduan Proses Perlakuan Panas, Lembaga Penelitian Institut Teknologi Bandung.

Surdia, T and Saito, S, 1985, Pengetahuan Bahan Teknik, PT. Pradnya Paramita, Jakarta.

Van Vlack, 1991, Ilmu dan Teknologi Bahan, Edisi 5, Alih Bahasa Sriati Djaprie , Penerbit Erlangga, Jakarta.

William D. Callister, Jr., 2000, Fundamentals of Materials Science and Engineering, An Interactive e text, John Wiley \& Sons, Inc.

http://www.lucchini.com.

http://www.matweb.com.

http://www.keytometal.com. 